\title{
Cytospolides A-E, New Nonanolides from an Endophytic Fungus, Cytospora $S p$.
}

\author{
Shan Lu, ${ }^{[a]}$ Tibor Kurtán, ${ }^{[b]}$ Genjin Yang, ${ }^{[a]}$ Peng Sun, ${ }^{[a]}$ Attila Mándi, ${ }^{[b]}$ Karsten Krohn, ${ }^{[c]}$ \\ Siegfried Draeger, ${ }^{[\mathrm{d}]}$ Barbara Schulz, ${ }^{[\mathrm{d}]}$ Yanghua Yi, ${ }^{[\mathrm{a}]}$ Ling Li, ${ }^{*[\mathrm{a}]}$ and Wen Zhang*[a]
}

Keywords: Natural products / Antitumor agents / Configuration determination / Nonanolide / Cytospolide

\section{Introduction}

Naturally occurring nonanolides (or decanolides) are a large family of secondary metabolites with an interesting 10-membered macrolide subunit. Metabolites of the nonanolide family can be roughly divided into two groups accord-

31 ing to the structural features of the side chain: (i) simple nonanolides with a methyl group at C-9 and (ii) nonanolides with extended alkyl chains at C-9. Structurally complex nonanolides with additional rings are sometimes also included in the family. ${ }^{[1]}$ The first member of this fascinating group of metabolites, jasmine keto lactone, was isolated and structurally elucidated in 1964 from Jasminum grandiflorium. ${ }^{[2]}$ In the years that followed, a series of nonanolides have been continuously reported from a variety of natural sources, which demonstrate various biological activities. ${ }^{[1,3]}$

The broad spectrum of bioactivity and the intriguing structure of the medium-sized ring in nonanolide analogues have attracted great interest as targets for total synthesis ${ }^{[4,5]}$ and biosynthetic studies. ${ }^{[1,3 \mathrm{v}]}$ Interestingly, the carbon skeletons

[a] Research Center for Marine Drugs, School of Pharmacy, Second Military Medical University,

325 Guo-He Road, Shanghai, 200433, P. R. China

E-mail: lilingty@hotmail.com zhangwen68@hotmail.com

[b] Department of Organic Chemistry, University of Debrecen, POB 20, 4010 Debrecen, Hungary

[c] Department Chemie, Universität Paderborn, Warburger Strasse 100, 33098 Paderborn, Germany

[d] Institut für Mikrobiologie, Technische Universität Braunschweig,

Spielmannstrasse 7, 31806 Braunschweig, Germany

Supporting information for this article is available on the WWW under http://dx.doi.org/10.1002/ejoc.201100675.
TD-DFT approaches. The cytotoxicity assay of C-2 epimers showed significantly different activity against A549, suggesting that the $\mathrm{C}-2$ methyl group has an important role in growth inhibition towards the tumor line. The existence of two conformers of the bioactive epimer in solution was proven by the soft pulse transfer NMR technique and further supported by DFT calculations. The discovery of the new metabolites not only extends the nonanolide family with cytospolide-type skeletons but also gives insight into the biosynthetic process of these fungal metabolites.

of all reported nonanolides, both natural and synthetic, are constructed with an even number of carbon atoms with extended C-9 alkyl chains, which are responsible for chemical diversity. To the best of our knowledge, there is no report on the nonanolide skeleton with an odd number of carbon atoms or with a C-2 alkyl chain.

During our ongoing screening for biologically active secondary metabolites from fungi, ${ }^{[6]}$ we recently investigated the endophytic fungus Cytospora sp., isolated from Ilex canariensis (Aquifoliaceae, Aquifoliales). Fractionation of the crude acetone extract led to the isolation and structural determination of four new 10-membered macrolides, the cytospolides 1-5 (Scheme 1). The carbon skeletons of 1-5 contain the unprecedented number of 15 carbon atoms with the unique chemical feature of a C-2 methyl group. In particular, an unexpected discovery was the isolation of both C-2 epimers from the same fungal extract. This stereochemical difference seems to be responsible for an amazing increase in the cytotoxic activity against the A549 cell line. The existence of two slowly exchanging solution conformers of the bioactive epimer was proven by the soft pulse transfer

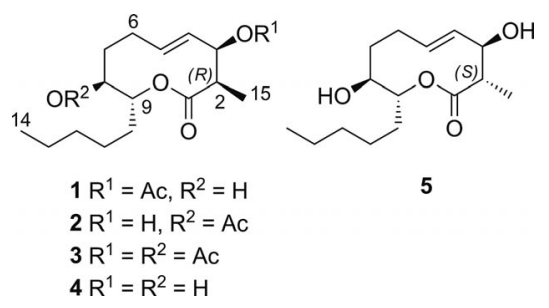

Scheme 1. Cytospolides $\mathbf{1}-\mathbf{5}$. 
NMR technique and supported by DFT calculations. Here we report the structure elucidation of the new metabolites using a combination of detailed spectroscopic analysis, chemical interconversion, and single-crystal XRD, the assignment of the absolute configurations using TD-DFT calculations of CD spectra, and their biological properties.

\section{Results and Discussion}

The fungus Cytospora $s p$. was cultivated on biomalt agar medium for four weeks and then extracted into acetone. The crude extract was fractionated on silica gel to yield crude mixtures of 1-5, which were further purified by silica column chromatography or semipreparative reversed phase (RP)-HPLC.

Cytospolide $\mathbf{1}$ was obtained as optically active colorless crystals $\left([\alpha]_{\mathrm{D}}^{20}=-119.3, c=0.19\right.$ in $\left.\mathrm{CHCl}_{3}\right)$. The molecular formula of $\mathrm{C}_{17} \mathrm{H}_{28} \mathrm{O}_{5}$ was established by HRMS, indicating four double bond equivalents. The IR spectrum of 1 showed absorptions from hydroxy $\left(3506 \mathrm{~cm}^{-1}\right)$ and ester groups $\left(1741 \mathrm{~cm}^{-1}\right)$. This observation is in agreement with the signals in the ${ }^{13} \mathrm{C}$ NMR and DEPT spectra (Table 1) for four $\mathrm{sp}^{2}$ carbon atoms $(2 \times \mathrm{OC}=\mathrm{O}, \mathrm{CH}=\mathrm{CH})$ at low field and thirteen $\mathrm{sp}^{3}$ carbon atoms at high field $\left(1 \times \mathrm{CH}, 6 \times \mathrm{CH}_{2}\right.$, $3 \times \mathrm{CH}_{3}, 3 \times \mathrm{OCH}$ ), accounting for three double bond equivalents. The remaining double bond equivalent was due to the presence of one ring in the molecule.

The HSQC spectrum facilitated the assignment of the protons to the corresponding carbon atoms (Table 1), and the ${ }^{1} \mathrm{H}-{ }^{1} \mathrm{H}$ COSY spectrum gave the proton sequence from $\mathrm{CH}_{3}-15$ to $\mathrm{CH}_{3}-14$. The observation of $\mathrm{HMBC}$ correlation from both $\mathrm{H}-2$ and $\mathrm{H}-9$ to $\mathrm{C}-1$ led to the formation of the 10-membered lactone ring (Figure 1); a C-3 acetoxy substitution was inferred from its remarkable downfield proton signal $\left(\delta_{\mathrm{H}}=5.35\right)$ in comparison with that of $\mathrm{H}-8\left(\delta_{\mathrm{H}}=\right.$ 3.65).

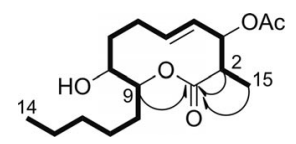

Figure 1. ${ }^{1} \mathrm{H}-{ }^{1} \mathrm{H}$ COSY (bond) and selected HMBC (arrow) correlations of $\mathbf{1}$.

The relative stereochemistry of $\mathbf{1}$ was deduced from the ${ }^{1} \mathrm{H}-{ }^{1} \mathrm{H}$ coupling constants and NOESY data (Figure 2). The geometry of the $\Delta^{4}$ double bond was assigned as $E$ based on the proton coupling constant $\left({ }^{3} J_{\mathrm{H} 4, \mathrm{H} 5}=16.2 \mathrm{~Hz}\right)$. The NOE cross peaks between $\mathrm{H}-9$ and $\mathrm{H}-5$, and $\mathrm{H}-7 \beta$, indicated a $\beta$ configuration of these protons. The obvious NOE effect between H-4 and both H-2 and H- $6 \alpha$, and between H- $6 \alpha$ and H-8, suggested that these protons have an $\alpha$-axial orientation. The $\alpha$ orientation of $\mathrm{H}-3$ was deduced from the NOE effect between $\mathrm{H}-3$ and both $\mathrm{H}-2$ and $\mathrm{H}_{3-}$ 15. The small proton coupling constant between $\mathrm{H}-2$ and $\mathrm{H}-3\left({ }^{3} J_{\mathrm{H} 2, \mathrm{H} 3}=3.6 \mathrm{~Hz}\right)$ supported the above conclusion, suggesting an equatorial position of $\mathrm{H}-3$.

Table 1. NMR spectroscopic data for $\mathbf{1}-$. $^{[a]}$

\begin{tabular}{|c|c|c|c|c|c|c|c|c|}
\hline & 1 & & 2 & & 3 & & 4 & \\
\hline & $\delta_{\mathrm{H}}, \mathrm{m}, J$ in $\mathrm{Hz}$ & $\delta_{\mathrm{C}}, \mathrm{m}$ & $\delta_{\mathrm{H}}, \mathrm{m}, J$ in $\mathrm{Hz}$ & $\delta_{\mathrm{C}}, \mathrm{m}$ & $\delta_{\mathrm{H}}, \mathrm{m}, J$ in $\mathrm{Hz}$ & $\delta_{\mathrm{C}}, \mathrm{m}$ & $\delta_{\mathrm{H}}, \mathrm{m}, J$ in $\mathrm{Hz}$ & $\delta_{\mathrm{C}}, \mathrm{m}$ \\
\hline 1 & & $172.4, \mathrm{~s}$ & & $173.7, \mathrm{~s}$ & & 171.7, s & & $174.5, \mathrm{~s}$ \\
\hline 2 & $2.74, \mathrm{qd}, 7.2,3.6$ & $45.0, \mathrm{~d}$ & $2.71, \mathrm{qd}, 7.2,3.6$ & $46.6, d$ & $2.74, \mathrm{qd}, 7.0,3.2$ & $45.0, \mathrm{~d}$ & $\begin{array}{l}2.69, \mathrm{qd}, 7.0, \\
3.2\end{array}$ & $46.7, \mathrm{~d}$ \\
\hline 3 & 5.35 , br. s & $72.5, \mathrm{~d}$ & 4.32 , br. s & $72.1, \mathrm{~d}$ & 5.35 , br. s & $72.6, \mathrm{~d}$ & 4.30 , br. s & $72.0, \mathrm{~d}$ \\
\hline 4 & $5.59, \mathrm{dd}, 16.2,2.4$ & $128.9, \mathrm{~d}$ & $5.66, \mathrm{dd}, 16.2,2.4$ & $133.3, \mathrm{~d}$ & $5.64, \mathrm{dd}, 16.2,2.8$ & $129.0, \mathrm{~d}$ & 5.61, ov & $133.2, \mathrm{~d}$ \\
\hline 5 & 5.55, ddd, $16.2,9.0,4.2$ & 129.6, d & $\begin{array}{l}5.61 \text {, ddd, } 16.2,9.0 \text {, } \\
4.2\end{array}$ & 127.2, d & $\begin{array}{l}5.55, \text { ddd, } 16.2,9.7 \\
5.1\end{array}$ & $129.2, \mathrm{~d}$ & $5.61, \mathrm{ov}$ & 127.7, d \\
\hline $6 \alpha$ & $2.11, \mathrm{~m}$ & $29.1, \mathrm{t}$ & $2.24, \mathrm{~m}$ & $28.8, \mathrm{t}$ & $2.20, \mathrm{~m}$ & $29.2, \mathrm{t}$ & $2.15, \mathrm{~m}$ & $28.4, \mathrm{t}$ \\
\hline $6 \beta$ & $2.36, \mathrm{~m}$ & & $2.29, \mathrm{~m}$ & & $2.25, \mathrm{~m}$ & & $2.38, \mathrm{~m}$ & \\
\hline $7 \alpha$ & $2.00, \mathrm{~m}$ & $38.1, \mathrm{t}$ & $1.88, \mathrm{~m}$ & $35.5, \mathrm{t}$ & $1.88, \mathrm{~m}$ & $35.3, \mathrm{t}$ & $1.99, \mathrm{~m}$ & $38.1, \mathrm{t}$ \\
\hline $7 \beta$ & $1.83, \mathrm{~m}$ & & $1.88, \mathrm{~m}$ & & $1.88, \mathrm{~m}$ & & $1.85, \mathrm{~m}$ & \\
\hline 8 & $3.65, \mathrm{t}, 7.2$ & $73.9, \mathrm{~d}$ & $4.77, \mathrm{td}, 7.2,1.8$ & $75.2, \mathrm{~d}$ & $4.75, \mathrm{td}, 7.6,1.2$ & $75.1, \mathrm{~d}$ & $3.66, \mathrm{t}, 7.1$ & $73.9, \mathrm{~d}$ \\
\hline 9 & $4.78, \mathrm{td}, 7.8,3.9$ & $77.7, \mathrm{~d}$ & $4.94, \mathrm{td}, 7.8,4.0$ & $75.8, \mathrm{~d}$ & $4.94, \mathrm{td}, 7.3,4.1$ & $75.6, \mathrm{~d}$ & $4.77, \mathrm{td}, 7.4,4.0$ & $77.9, \mathrm{~d}$ \\
\hline $10 \mathrm{a}$ & $1.74, \mathrm{~m}$ & $32.1, \mathrm{t}$ & $1.61, \mathrm{~m}$ & $31.9, \mathrm{t}$ & $1.61, \mathrm{~m}$ & $32.0, \mathrm{t}$ & $1.72, \mathrm{~m}$ & $32.1, \mathrm{t}$ \\
\hline $10 b$ & $1.55, \mathrm{~m}$ & & $1.45, \mathrm{~m}$ & & $1.45, \mathrm{~m}$ & & $1.54, \mathrm{~m}$ & \\
\hline $11 \mathrm{a}$ & $1.28, \mathrm{~m}$ & $24.3, \mathrm{t}$ & $1.22, \mathrm{~m}$ & $24.2, \mathrm{t}$ & $1.22, \mathrm{~m}$ & $24.1, \mathrm{t}$ & $1.29, \mathrm{~m}$ & $24.4, \mathrm{t}$ \\
\hline $11 b$ & $1.28, \mathrm{~m}$ & & $1.22, \mathrm{~m}$ & & $1.22, \mathrm{~m}$ & & $1.29, \mathrm{~m}$ & \\
\hline $12 \mathrm{a}$ & $1.28, \mathrm{~m}$ & $31.8, \mathrm{t}$ & $1.25, \mathrm{~m}$ & $31.7, \mathrm{t}$ & $1.25, \mathrm{~m}$ & $31.7, \mathrm{t}$ & $1.29, \mathrm{~m}$ & $31.8, \mathrm{t}$ \\
\hline $12 b$ & $1.28, \mathrm{~m}$ & & $1.25, \mathrm{~m}$ & & $1.25, \mathrm{~m}$ & & $1.29, \mathrm{~m}$ & \\
\hline $13 a$ & $1.28, \mathrm{~m}$ & $22.5, \mathrm{t}$ & $1.26, \mathrm{~m}$ & $22.4, \mathrm{t}$ & $1.25, \mathrm{~m}$ & $22.5, \mathrm{t}$ & $1.28, \mathrm{~m}$ & $22.5, \mathrm{t}$ \\
\hline $13 b$ & $1.28, \mathrm{~m}$ & & $1.26, \mathrm{~m}$ & & $1.25, \mathrm{~m}$ & & $1.28, \mathrm{~m}$ & \\
\hline 14 & $0.88, \mathrm{t}, 6.9$ & $14.0, \mathrm{q}$ & $0.86, \mathrm{t}, 6.8$ & $14.0, \mathrm{q}$ & $0.86, \mathrm{t}, 6.7$ & $14.0, \mathrm{q}$ & $0.88, \mathrm{t}, 6.6$ & $14.0, \mathrm{q}$ \\
\hline 15 & $1.18, \mathrm{~d}, 7.0$ & $12.2, \mathrm{q}$ & $1.29, \mathrm{~d}, 7.0$ & $12.5, \mathrm{q}$ & $1.18, \mathrm{~d}, 7.1$ & $12.3, \mathrm{q}$ & $1.28, \mathrm{~d}, 6.9$ & $12.4, \mathrm{q}$ \\
\hline \multirow[t]{2}{*}{ 3-OAc } & $2.14, \mathrm{~s}$ & $170.4, \mathrm{~s}$ & & & $2.14, \mathrm{~s}$ & $170.3, \mathrm{~s}$ & & \\
\hline & & $20.9, \mathrm{q}$ & & & & $20.9, \mathrm{q}$ & & \\
\hline \multirow[t]{2}{*}{ 8-OAc } & & & $2.07, \mathrm{~s}$ & $169.9, \mathrm{~s}$ & $2.06, \mathrm{~s}$ & $169.9, \mathrm{~s}$ & & \\
\hline & & & & $21.2, \mathrm{q}$ & & $21.2, \mathrm{q}$ & & \\
\hline
\end{tabular}

[a] In $\mathrm{CDCl}_{3}$, assignments made by DEPT, ${ }^{1} \mathrm{H}-{ }^{1} \mathrm{H}$ COSY, HSQC, HMBC, and NOESY. 


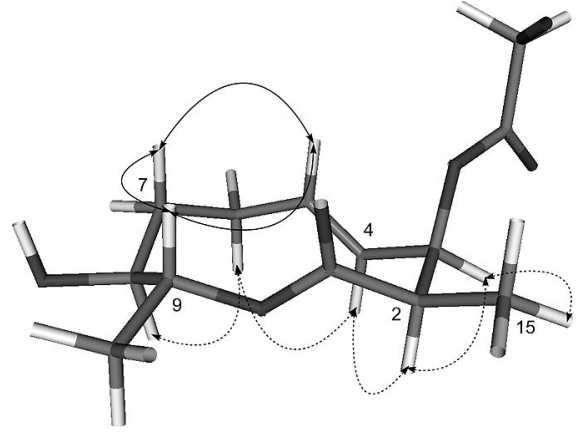

Figure 2. Key NOESY correlations of 1 indicated on the lowestenergy DFT solution conformer.

The structure and relative stereochemistry of 1 were further confirmed by single-crystal X-ray analysis. The most likely absolute chemistry of $\mathbf{1}$ was suggested to be $(2 R, 3 R, 8 S, 9 R)$ by the absolute structure parameter 0.1 (2) of the X-ray analysis, showing two slightly different conformers in a 1:1 ratio in the crystal depicted in Figure 3. This absolute configuration was further confirmed by the solid state CD/TD-DFT approach, ${ }^{[7]}$ in which the geometry of the DFT-optimized X-ray structure is used as input for TD-DFT CD calculations, ${ }^{[8]}$ and the resultant computed CD spectrum is compared with the solid state CD spectrum measured from a microcrystalline $\mathrm{KCl}$ pellet. This method is especially useful for the configurational assignment of conformationally flexible natural products as it does not require any conformational analysis. ${ }^{[7]}$ a)

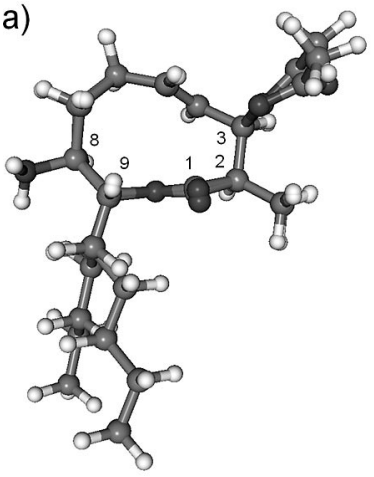

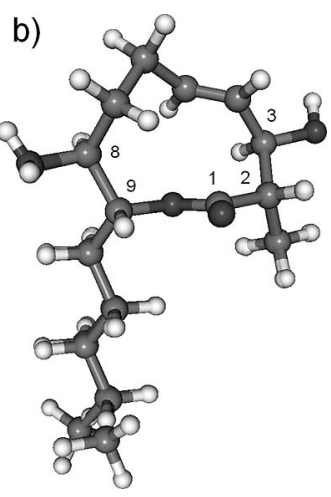

Figure 3. Superposition of the two DFT-optimized X-ray structures of 1 (a) and $\mathbf{5}$ (b).

The solution CD spectrum of $\mathbf{1}$ showed a weak positive $\mathrm{n}-\pi^{*}$ Cotton effect (CE) at $224.5 \mathrm{~nm}$ and an intense negative $\pi-\pi^{*} \mathrm{CE}$ at $196 \mathrm{~nm}$ (Figure 4). The solid state CD spectrum $(\mathrm{KCl})$ also showed a negative $\pi-\pi^{*}$ transition, with a negative shoulder appearing in the $\mathrm{n}-\pi^{*}$ region above $220 \mathrm{~nm}$, indicating the conformational flexibility of the molecule. CD spectra were calculated with three different functionals as the weighted average of the two DFT-optimized geometries (1:1 ratio), which differed only in the arrangement of the C-9 alkyl chain, the $\mathrm{OH}$, and the acetate group. The CD spectra computed for the $(2 R, 3 R, 8 S, 9 R)$ enanti- omer were in good agreement with the solid state CD spectrum, allowing the determination of the absolute configuration as $(2 R, 3 R, 8 S, 9 R)$.

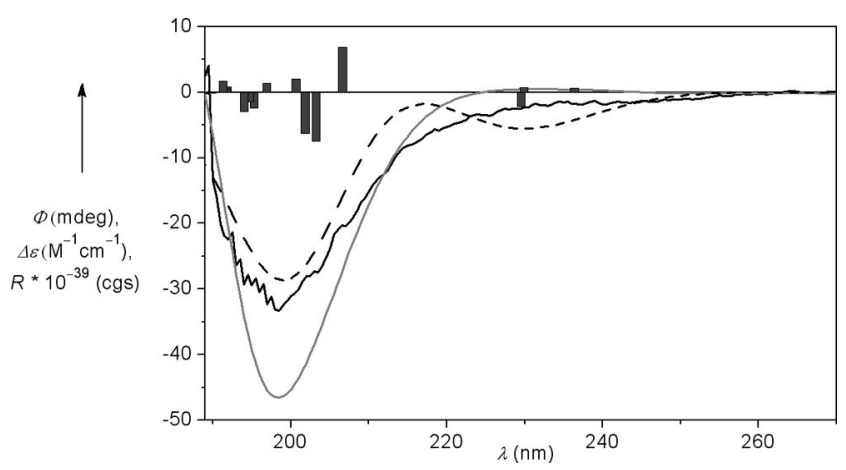

Figure 4. Experimental solution (grey line) and solid state (black line) CD spectra of cytospolide 1 [ $(2 R, 3 R, 8 S, 9 R)-1]$ compared with the averaged $\mathrm{B} 3 \mathrm{LYP} / \mathrm{TZVP}$ spectrum calculated for $(2 R, 3 R, 8 S, 9 R)$ enantiomers of the X-ray geometries (dashed line). Bars represent rotational strength calculated with B3LYP/TZVP method for conformer $\mathrm{A}$.

As the collection of high theta reflections was insufficient due to the quality of the crystal of $\mathbf{1}$, a Merck molecular force field (MMFF) conformational search was carried out on the model compound of $\mathbf{1}$ containing a methyl group instead of the C-9 pentyl chain. The MMFF conformational search (Macromodel) resulted in 33 conformers within a $21 \mathrm{~kJ} / \mathrm{mol}$ energy window, which, after reoptimization at B3LYP/6-31G(d) level in the gas phase, afforded seven clusters with $95.5 \%$ overall population (Figure S1, Supporting Information). However, the distribution of the computed conformers was not fully in agreement with the results of the X-ray analysis and solution NMR spectroscopic data (see details in the Supporting Information).

Thus the B3LYP/6-31G(d) reoptimizations of the MMFF conformers was repeated with an implicit solvent model for chloroform. The $3-\mathrm{OAc}_{\mathrm{ax}}, 8-\mathrm{OH}_{\mathrm{eq}}$ conformer, identical to that obtained from X-ray analysis, was found to be the lowest-energy and most abundant conformer with a total population of $87.7 \%$ (sum of three slightly different conformers with $46.1,27.1$, and $14.5 \%$ populations, Figure S2), which was in accordance with the solution coupling constant data and NOE effects as well as the X-ray geometry.

Cytospolide $\mathbf{2}$ was isolated as an optically active colorless oil. The molecular formula of $\mathrm{C}_{17} \mathrm{H}_{28} \mathrm{O}_{5}$, established by HRMS, was the same as that of $\mathbf{1}$. The IR and UV spectra of $\mathbf{2}$ closely resemble those of $\mathbf{1}$, showing similar functionalities in the molecule. Analysis of ${ }^{1} \mathrm{H}$ and ${ }^{13} \mathrm{C}$ NMR spectra of $\mathbf{2}$ also revealed similarities to those of $\mathbf{1}$ (Table 1). However, the acetoxy group is assigned to C-8 in $\mathbf{2}$ instead of $\mathrm{C}-3$ in $\mathbf{1}$ due to the difference in chemical shifts of the H-3 and $\mathrm{H}-8$ methine protons $\left(\delta_{3 \mathrm{H}}=5.35\right.$ in $1, \delta_{8 \mathrm{H}}=4.77$ in 2). The assignment was further confirmed by the proton sequence from $\mathrm{CH}_{3}-15$ to $\mathrm{CH}_{3}-14$ established by the ${ }^{1} \mathrm{H}-{ }^{1} \mathrm{H}$ COSY spectrum, and the long-range correlation from $\mathrm{H}$ 8 to the acetyl carbonyl group deduced from the HMBC spectrum. Acetylation of $\mathbf{2}$ afforded the 3,8-diacetoxy deriv- 
ative identical to the acetylation product of $\mathbf{1}$ in all respects, including MS, NMR, and $[\alpha]_{\mathrm{D}}^{20}$ values. The structure of $\mathbf{2}$

181 was thus determined and the absolute stereochemistry was assigned as (-)- $(2 R, 3 R, 8 S, 9 R)$.

Cytospolide $\mathbf{3}$ was isolated as an optically active colorless oil. Its molecular formula was determined as $\mathrm{C}_{19} \mathrm{H}_{30} \mathrm{O}_{6}$ by HRMS. The absorption band from the hydroxy groups disappeared from the IR spectrum. The ${ }^{1} \mathrm{H}$ NMR spectrum of $\mathbf{3}$ was similar to that of $\mathbf{1}$, except for the presence of an additional methyl signal at $\delta_{\mathrm{H}}=2.06$ (s) (Table 1). This signal, in conjunction with two carbon resonances at $\delta_{\mathrm{C}}=$ 169.9 (s) and 21.2 (q) in its ${ }^{13} \mathrm{C}$ NMR spectrum (Table 1), suggested the presence of an additional acetyl group in $\mathbf{3}$. The location of the acetoxy group at C-8 was suggested by the downfield shift of the respective proton signal at $\mathrm{C}-8$ $\left(\delta_{\mathrm{H}}=3.65\right.$ in $\mathbf{1}, \delta_{\mathrm{H}}=4.75$ in 3 ). An additional structural proof came from chemical interconversion; acetylation of $\mathbf{1}$ afforded 3 with identical MS, NMR, and $[\alpha]_{\mathrm{D}}^{20}$ values. Thus, the structure and absolute stereochemistry of $\mathbf{3}$ were determined as the 8-acetyl derivative of $\mathbf{1}$.

Cytospolide 4, the major metabolite of the fungus, was also isolated as an optically active colorless oil. Its molecu201 lar formula of $\mathrm{C}_{15} \mathrm{H}_{26} \mathrm{O}_{4}$ was established by HRMS. Its UV, IR, ${ }^{1} \mathrm{H}$ and ${ }^{13} \mathrm{C}$ NMR spectroscopic data (Table 1) were very similar to those of $\mathbf{1}$, suggesting that they share the same framework. In fact, the absence of an acetyl group compared to $\mathbf{1}$ was the only difference recognized in the

206 spectroscopic data of 4. Furthermore, the upfield-shifted ${ }^{1} \mathrm{H}$ NMR resonance of $\mathrm{H}-3\left(\delta_{\mathrm{H}}=4.30\right.$ in $4,5.35$ in $\left.\mathbf{1}\right)$ indicated the presence of a hydroxy group instead of an acetyl group at C-3. Chemical correlation of $\mathbf{4}$ and $\mathbf{1}$ by acetylation confirmed the structure of $\mathbf{4}$ as the 3-deacetyl derivative of $\mathbf{1}$.

211 Cytospolide $\mathbf{5}$ was isolated as optically active colorless crystals $\left([\alpha]_{\mathrm{D}}^{20}=+33.3, c=0.09\right.$ in $\left.\mathrm{CHCl}_{3}\right)$. Its molecular formula of $\mathrm{C}_{15} \mathrm{H}_{26} \mathrm{O}_{4}$, established by HRMS, was the same as that of 4 . The ${ }^{1} \mathrm{H}$ and ${ }^{13} \mathrm{C}$ NMR spectra of $\mathbf{5}$ showed two set of signals with an approximately $4: 5$ ratio (Table 2 ).

216 The well separated resonance signals made it possible to elucidate the two structures from a detailed analysis of the 1D and 2D NMR experiments, including ${ }^{1} \mathrm{H},{ }^{13} \mathrm{C}$ NMR, DEPT, HSQC, COSY, and HMBC. The planar structures corresponding to the two sets of signals were found to be identical to each other and the same as that of $\mathbf{4}$.

The observation of strong proton exchange signals of the coupled protons in the NOE spectra suggest that the coupled signals originate from two conformers of the same compound. The exchange between two equally populated conformers was proven by a magnetization transfer NMR technique, namely soft pulse transfer (SPT). ${ }^{[9]}$ The exchange-coupled resonance of $\mathrm{H}_{3}-15\left(\delta_{\mathrm{H}}=1.37\right.$ and 1.17 , Table 2) was selectively inverted and initiated with a weak pulse of radiofrequency power. The temporal response of 231 the exchanged-coupled resonances was then determined by observation of the resonance intensities after a variable delay time using determined Fourier transform techniques developed for inversion-recovery $\left(T_{1}\right)$ experiments. The intensities obtained after various delay times at $300 \mathrm{~K}$ are shown in Figure 5. It is clear that chemical exchange effects quali-
Table 2. NMR spectroscopic data for $\mathbf{5 a}$ and $\mathbf{5 b}$ solution conformers of 5. $^{\text {a] }}$

\begin{tabular}{lllll}
\hline No. & $\mathbf{5 a}$ & \multicolumn{3}{l}{$\mathbf{5 b}$} \\
\hline & $\delta_{\mathrm{H}}, \mathrm{m}, J$ in $\mathrm{Hz}$ & $\delta_{\mathrm{C}}, \mathrm{m}$ & $\delta_{\mathrm{H}}, \mathrm{m}, J$ in $\mathrm{Hz}$ & $\delta_{\mathrm{C}}, \mathrm{m}$ \\
\hline 1 & & $175.4, \mathrm{~s}$ & & $173.5, \mathrm{~s}$ \\
2 & $2.62, \mathrm{~m}$ & $50.9, \mathrm{~d}$ & $2.88, \mathrm{qd}, 7.2$, & $50.9, \mathrm{~d}$ \\
3 & $4.05, \mathrm{t}, 8.4$ & $77.7, \mathrm{~d}$ & $4.26, \mathrm{br} . \mathrm{s}$ & $72.5, \mathrm{~d}$ \\
4 & $5.44, \mathrm{dd}, 15.8,9.2$ & $130.5, \mathrm{~d}$ & $5.73, \mathrm{ov}$ & $129.7, \mathrm{~d}$ \\
5 & $5.71, \mathrm{ddd}, 15.8,10.6$, & $136.7, \mathrm{~d}$ & $5.73, \mathrm{ov}$ & $130.3, \mathrm{~d}$ \\
$6 \alpha$ & 2.7 & $26.5, \mathrm{t}$ & $2.15, \mathrm{~m}$ & $28.3, \mathrm{t}$ \\
$6 \beta$ & $2.28, \mathrm{~m}$ & & $2.38, \mathrm{~m}$ & \\
$7 \alpha$ & $1.77, \mathrm{~m}$ & $34.3, \mathrm{t}$ & $1.88, \mathrm{~m}$ & $37.9, \mathrm{t}$ \\
$7 \beta$ & $1.92, \mathrm{~m}$ & & $1.94, \mathrm{~m}$ & \\
8 & $3.83, \mathrm{t}, 6.2$ & $73.2, \mathrm{~d}$ & $3.68, \mathrm{t}, 6.6$ & $73.7, \mathrm{~d}$ \\
9 & $4.79, \mathrm{~m}$ & $78.9, \mathrm{~d}$ & $4.81, \mathrm{~m}$ & $78.1, \mathrm{~d}$ \\
$10 \mathrm{a}$ & $1.62, \mathrm{~m}$ & $31.1, \mathrm{t}$ & $1.69, \mathrm{~m}$ & $32.0, \mathrm{t}$ \\
$10 \mathrm{~b}$ & $1.62, \mathrm{~m}$ & & $1.57, \mathrm{~m}$ & \\
$11 \mathrm{a}$ & $1.28, \mathrm{~m}$ & $25.4, \mathrm{t}$ & $1.29, \mathrm{~m}$ & $24.3, \mathrm{t}$ \\
$11 \mathrm{~b}$ & $1.28, \mathrm{~m}$ & & $1.29, \mathrm{~m}$ & \\
$12 \mathrm{a}$ & $1.27, \mathrm{~m}$ & $31.4, \mathrm{t}$ & $1.27, \mathrm{~m}$ & $31.7, \mathrm{t}$ \\
$12 \mathrm{~b}$ & $1.27, \mathrm{~m}$ & & $1.27, \mathrm{~m}$ & \\
$13 \mathrm{a}$ & $1.30, \mathrm{~m}$ & $22.5, \mathrm{t}$ & $1.30, \mathrm{~m}$ & $22.5, \mathrm{t}$ \\
$13 \mathrm{~b}$ & $1.30, \mathrm{~m}$ & & $1.30, \mathrm{~m}$ & \\
14 & $0.87, \mathrm{t}, 6.7$ & $14.0, \mathrm{q}$ & $0.87, \mathrm{t}, 6.7$ & $14.0, \mathrm{q}$ \\
15 & $1.37, \mathrm{~d}, 7.0$ & $15.5, \mathrm{q}$ & $1.17, \mathrm{~d}, 7.2$ & $13.0, \mathrm{q}$ \\
\hline
\end{tabular}

[a] In $\mathrm{CDCl}_{3}$, assignments made by DEPT, ${ }^{1} \mathrm{H}-{ }^{1} \mathrm{H}$ COSY, HSQC, and $\mathrm{HMBC}$.

tatively manifest themselves in initial intensity loss in the first conformer $\left(\mathbf{5 a}, \delta_{\mathrm{H}}=1.37\right)$ due to the transfer of magnetization from the inverted resonance of the second conformer. The resonance of the second conformer $\left(\mathbf{5 b}, \delta_{\mathrm{H}}=\right.$ 1.17) reflects the presence of chemical exchange by relaxing more quickly than in the absence of exchange.

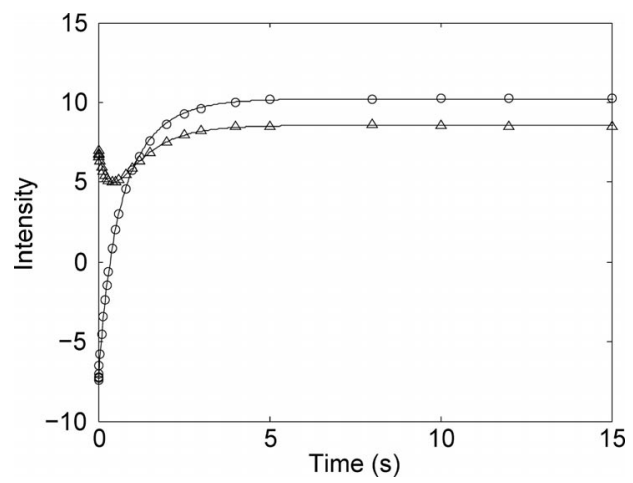

Figure 5. Relaxation behavior at $300 \mathrm{~K}$ of $\mathrm{H}_{3}-15$ of 5 ; a) observed intensities of the conformer $5 \mathbf{a}(\Delta)$; b) observed intensities of the conformer $\mathbf{5 b}(\bigcirc)$.

It is reasonable to observe large coupling constant values between $\mathrm{H}-3_{\mathrm{ax}}, \mathrm{H}-2_{\mathrm{ax}}$, and $\mathrm{H}-4_{\mathrm{ax}}$ in $\mathbf{5} \mathbf{a}$, which is reduced when the axial H-3 changes to equatorial in $\mathbf{5 b}$ (Table 2). The exchange signals of the two conformers is due to the high energy barrier of the conformational change involving a flip of $3-\mathrm{OH}$ from axial to equatorial while the $8-\mathrm{OH}$ remains unchanged. The origin for a relatively high energy barrier of the conformational interconversion of $\mathbf{5 a}$ and $\mathbf{5 b}$ is due to the presence of a trans-double bond in a medium- 
sized ring. In contrast, according to the DFT calculation and NMR spectroscopic data of $\mathbf{1}$ and $\mathbf{4}$, there is only one major conformer $\left(87.5 \% 3-\mathrm{OAc}_{\mathrm{ax}}, 8-\mathrm{OH}_{\mathrm{eq}}\right.$ conformer from DFT) of $\mathbf{4}$ in solution due to its different configuration.

256 Interestingly, $\mathbf{5}$ demonstrated a different NOE pattern to $\mathbf{4}$ (Figure 6). The relative configuration was mainly deduced from the NOE effect of $\mathbf{5 a}$ as its proton signals are well separated. Distinct NOE cross peaks between H-5 and H-3 and $\mathrm{H}-8$, and between $\mathrm{H}-3$ and $\mathrm{H}_{3}-15$, indicated that these protons were oriented on the same side of the lactone ring. The NOE effect between H-7 $\beta$ and H-4 and H-9, indicated a $\beta$ orientation of these protons (Figure 6). The geometry of the $\Delta^{4}$ double bond was determined as $E$ due to the large proton coupling constant $\left({ }^{3} J_{\mathrm{H} 4, \mathrm{H} 5}=15.8 \mathrm{~Hz}\right.$, Table 2). However, the double bond was half circle rotated with both protons oriented on the opposite side compared to those in 1-4. Obviously, H-2 and H-9 of 5 are located on the same side of the lactone ring in contrast to the situation in $\mathbf{4}$ where they were on opposite sides of the lactone ring. Thus

2715 is the $\mathrm{C}-2$ epimer of $\mathbf{4}$, which is also in accordance with the ${ }^{13} \mathrm{C}$ chemical shift difference of $\mathrm{C}-2$ in the two compounds $\left(\delta_{\mathrm{C}}=46.7\right.$ in $\mathbf{4}, 50.9$ in $\mathbf{5}$, see Tables 1 and 2$)$.

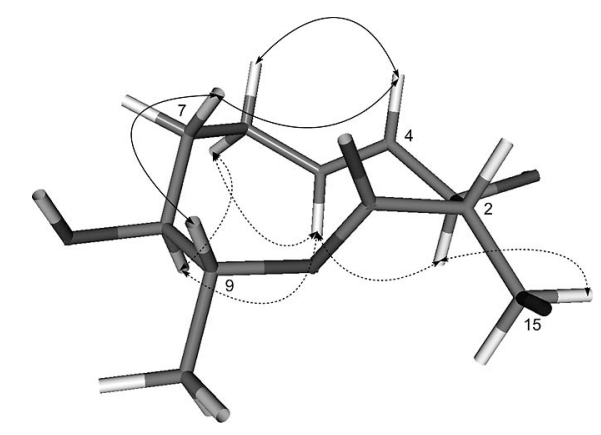

Figure 6. Key NOESY correlations of 5 shown on the lowest-energy $3-\mathrm{OH}_{\mathrm{eq}}, 8-\mathrm{OH}_{\mathrm{eq}}$ DFT solution conformer.

The structure and relative stereochemistry of $\mathbf{5}$ was further confirmed by single-crystal X-ray analysis (Figure 3), showing again two conformers in a 1:1 ratio in the crystal lattice. It is noteworthy that the two X-ray geometries have only minor differences in the conformation of the C-9 pentyl chain and thus they probably represent only one of the solution conformers (5a) responsible for the duplicate

281 NMR signals. The CD spectrum of $\mathbf{5}$ is dominated by transitions of the lactone chromophore, which in turn is predominantly governed by the absolute configuration of the adjacent C-2 chiral center. Thus, the opposite $\pi-\pi^{*} \mathrm{CE}$ of 5 at around $200 \mathrm{~nm}$ compared to that of $\mathbf{4}$ (Figure S3, Sup286 porting Information) indicates a different configuration at $\mathrm{C}-2$ and hence the $(2 S, 3 R, 8 S, 9 R)$ absolute configuration. Although the solid state CD spectrum of $\mathbf{5}$ could not be recorded due to the limited amount of crystalline $\mathbf{5}$ obtained, the solution $\mathrm{CD}$ curve could be reproduced well by

291 the averaged TD-DFT CD spectra calculated for the $(2 S, 3 R, 8 S, 9 R)$ enantiomer of the reoptimized two X-ray geometries, confirming the established absolute configuration (Figure S3).
Furthermore, the conformational analysis of the CD calculation was also used to support the insufficient collection of high theta reflections of the crystal of $\mathbf{5}$. A MMFF conformational search was carried out on the model of $\mathbf{5}$ containing a C-9 methyl instead of the pentyl group. The solution conformers were reoptimized at the B3LYP/6-31G(d) level in the gas phase, the result of which was against the measured NOE effects and ${ }^{3} J_{\mathrm{H}, \mathrm{H}}$ data, since $3-\mathrm{OH}_{\mathrm{ax}}, 8$ $\mathrm{OH}_{\mathrm{ax}}$ and $3-\mathrm{OH}_{\mathrm{ax}}, 8-\mathrm{OH}_{\mathrm{eq}}$ conformers were found to be dominant with 43.6 and $34.5 \%$ overall population, respectively (for details see Supporting Information, Figure S4). In order to improve the correlation with the spectroscopic data, the DFT reoptimization was repeated with an implicit solvent model for chloroform. The two equilibrating conformers observed in solution by NMR could then be identified as $3-\mathrm{OH}_{\mathrm{eq}}, 8-\mathrm{OH}_{\mathrm{eq}}$ and $3-\mathrm{OH}_{\mathrm{ax}}, 8-\mathrm{OH}_{\mathrm{eq}}$, which were the two most populated conformers in solution, although their calculated relative populations (10.1 and $71.3 \%)$ were markedly different from the nearly 4:5 ratio observed experimentally (Figure S5). As the most abundant calculated solution conformer $\left(3-\mathrm{OH}_{\mathrm{ax}}, 8-\mathrm{OH}_{\mathrm{eq}}\right)$ was different from the $3-\mathrm{OH}_{\mathrm{eq}}, 8-\mathrm{OH}_{\mathrm{eq}}$ solid state conformer, the $\mathrm{CD}$ of the lowest energy $3-\mathrm{OH}_{\mathrm{ax}}, 8-\mathrm{OH}_{\mathrm{eq}}$ conformer was also calculated and compared with the experimental solution curve (Figure 7). The CD spectrum calculated for the $(2 S, 3 R, 8 S, 9 R)$ enantiomer had a positive CE above $200 \mathrm{~nm}$, which confirmed the previous configurational assignment.

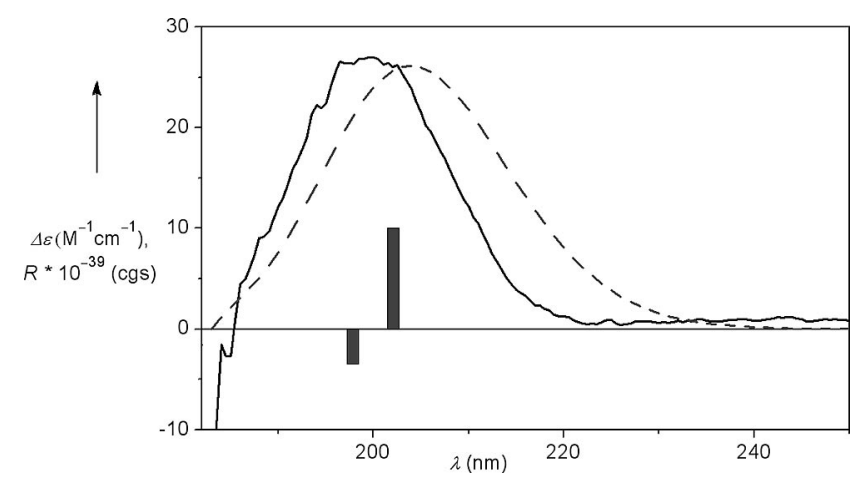

Figure 7. Experimental solution CD spectrum (solid line) of $\mathbf{5}$ compared with that computed with PBE0/TZVP in chloroform (dashed line) for the most abundant $3-\mathrm{OH}_{\mathrm{ax}}, 8-\mathrm{OH}_{\mathrm{eq}}$ conformer of the truncated model compound obtained from B3LYP/6-31G(d) optimizations in chloroform. Bars represent rotational strength calculated by the PBE0/TZVP method.

The structurally most related metabolites, putaminoxins $\mathrm{B}$ and $\mathrm{D}$, were isolated previously from a pathogenic fungus Phoma putaminum..$^{[3 \mathrm{~s}, 3 \mathrm{t}]}$ The carbon skeleton of putaminoxins $\mathrm{B}$ and $\mathrm{D}$ differs from that of $\mathbf{1}-\mathbf{5}$ by the absence of a C-2 methyl group. The discovery of an array of new nonanolides demonstrates the chemical diversity and extend the nonanolide family by a new carbon skeleton with the unique structural feature of a C-2 methyl group. The appearance of an additional methyl group in 1-5 suggests a different biogenetic route from the polyketide pathway found in the fungal nonanolides of aspinolides ${ }^{[3 \mathrm{v}]}$ and decarestrictines. ${ }^{[10]}$ The C-2 methyl group of the cytospolides can be 
incorporated by two possible biosynthetic pathways. Methylmalonyl-CoA instead of malonyl-CoA may be used as the

336 final extender unit in the PKS elongation process of cytospolides in contrast to that of other nonanolides (Figure 8, A). The other possible way for the incorporation of the methyl group may occur by enzymatic methylation using $S$ adenosylmethionine during posttranslational modifications,

341 which is involved in numerous biochemical processes in animals, plants and microorganisms (Figure 8, B). ${ }^{[1]}$ The isolation of both C-2 epimers as metabolites from one fungus is quite unusal. The isolation protocol was repeated on $10 \mathrm{mg}$ of pure $\mathbf{4}$, which did not even show traces of $\mathbf{5}$. Actu346 ally, the low acidity of the $2-\mathrm{CH} \alpha$ to the ester $\left(\mathrm{p} K_{\mathrm{a}} \approx 25\right)$ makes it unlikely that epimerization would occur after the biosynthesis but more likely if the last ketide extension during biosynthesis gave rise to a longer-lived bis- $\beta$-ketothioester intermediate, which is far more acidic $\left(\mathrm{p} K_{\mathrm{a}} \approx 7-9\right)$.

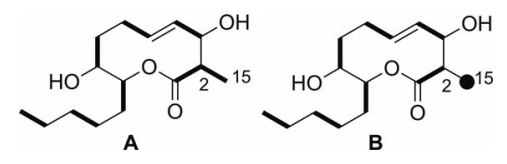

Figure 8. Two possible biosynthetic pathways of incorporation of C-2 methyl in cytospolides.

351 It is noteworthy that inversion of the absolute configuration at C-2 from $(2 R)$ of $\mathbf{4}$ to $(2 S)$ of $\mathbf{5}$ leads to a surprising increase in cytotoxic activity. In a cytotoxic in vitro bioassay, 1, 3, and $\mathbf{4}$ showed no activity against the A-549 cell line at $50.0 \mu \mathrm{g} / \mathrm{mL}$, whereas $\mathbf{2}$ and $\mathbf{5}$ displayed strong cyto-

356 toxic activity with $\mathrm{IC}_{50}$ values of 5.15 and $7.09 \mu \mathrm{g} / \mathrm{mL}$, respectively. The $8-O$-monoacetate and the absolute configuration on C-2 clearly play important roles in the growth inhibition of the tumor line.

The isolation of the C-2 methyl nonanolides from the

361 fungal extract gives insight into the biosynthetic process of the metabolite. The new structures, the cytotoxic activity, and the structure-activity relationship may encourage further investigations by natural product chemists, synthetic chemists, and pharmacists.

\section{Experimental Section}

General Experimental Procedures: Commercial silica gel (Yantai, P. R. China, 200-300; 400-500 mesh) was used for column chromatography. Precoated silica gel plates (Yantai, P. R. China, HSGF-254) were used for analytical TLC. Spots were detected on

371 TLC under UV or by heating after spraying with an anisaldehydesulfuric acid reagent. TLC $R_{\mathrm{f}}$ values are reported. The NMR spectra were recorded at $293 \mathrm{~K}$ with a Bruker Avance 600 spectrometer. Chemical shifts are reported in parts per million $(\delta)$, with the residual $\mathrm{CDCl}_{3}$ signal $\left(\delta_{\mathrm{H}}=7.26 \mathrm{ppm}\right)$ as an internal standard for ${ }^{1} \mathrm{H}$

$376 \mathrm{NMR}$ and $\mathrm{CDCl}_{3}\left(\delta_{\mathrm{C}}=77.0 \mathrm{ppm}\right)$ for ${ }^{13} \mathrm{C} \mathrm{NMR}$; coupling constants $(J)$ in $\mathrm{Hz} .{ }^{1} \mathrm{H}$ NMR and ${ }^{13} \mathrm{C}$ NMR assignments were supported by ${ }^{1} \mathrm{H}-{ }^{1} \mathrm{H}$ COSY, HSQC, HMBC, and NOESY experiments. The following abbreviatons are used to describe spin multiplicity: $\mathrm{s}=$ singlet, $\mathrm{d}=$ doublet, $\mathrm{t}=$ triplet, $\mathrm{q}=$ quartet, $\mathrm{m}=$ mul-

381 tiplet, br. $\mathrm{s}=$ broad singlet, $\mathrm{dd}=$ doublet of doublets, $\mathrm{ddd}=$ doublet of doublets of doublets, $\mathrm{dt}=$ doublet of triplets, $\mathrm{qd}=$ quartet of doublets, ov $=$ overlapped signals. Optical rotations were mea- sured in $\mathrm{CHCl}_{3}$ with an Autopol IV polarimeter at the sodium D line $(590 \mathrm{~nm})$. Infrared spectra were recorded in thin polymer films with a Nexus 470 FTIR spectrophotometer; peaks are reported in $\mathrm{cm}^{-1}$. Melting points were determined with an XT5-XMT micro melting point apparatus and are uncorrected. UV absorption spectra were recorded with a Varian Cary $100 \mathrm{UV} / \mathrm{Vis}$ spectrophotometer; wavelengths are reported in $\mathrm{nm}$. CD spectra were recorded with a Jasco-715 spectropolarimeter. See ref. ${ }^{[7]}$ for the solid state CD protocol. The mass spectra and high-resolution mass spectra were performed with a Q-TOF Micro mass spectrometer, resolution 5000. An isopropyl alcohol solution of sodium iodide $(2 \mathrm{mg} / \mathrm{mL})$ was used as a reference compound. The X-ray diffraction study was carried out with a Bruker SMART APEX-II CCD diffractometer with $\mathrm{Cu}-K_{\alpha}$ radiation $(\lambda=1.542178 \AA)$. Semipreparative RP-HPLC was performed with an Agilent 1100 system equipped with a refractive index detector using a YMC Pack ODSA column (particle size $5 \mu \mathrm{m}, 250 \times 10 \mathrm{~mm}$ ).

Culture, Extraction and Isolation: The endophytic fungus Cytospora $s p$., internal strain no. ZW02, was isolated following surface sterilization from Ilex canariensis, a woody, evergreen shrub from Gomera in Spain in 2007. The fungal strain was isolated and identified by Dr. Siegfried Draeger (Institut für Mikrobiologie, Technische Universität Braunschweig, Germany) and a voucher specimen is deposited in the culture collection of Institut für Mikrobiologie, Technische Universität Braunschweig. The fungus Cytospora sp. was cultivated on biomalt ( $5 \%$ w/v; Villa Natura Gesundprodukte $\mathrm{GmbH}$, Kirn, Germany) solid agar medium at room temperature for 28 days. ${ }^{[12]}$ The culture medium was then extracted into acetone to afford a residue $(9.98 \mathrm{~g})$ after removal of the solvent under reduced pressure. The extract was subjected to column chromatography (CC) on silica gel, eluted with a gradient of $\mathrm{CH}_{2} \mathrm{Cl}_{2}$ in acetone $(100: 1,80: 20,50: 50,30: 70,1: 100 \mathrm{v} / \mathrm{v})$, to give 17 subfractions. Fractions 2 and 3 were first purified on silica gel CC (400500 mesh, $\mathrm{CH}_{2} \mathrm{Cl}_{2}$ /acetone, 100:1), and then subjected to RPHPLC $\left(\mathrm{MeOH} / \mathrm{H}_{2} \mathrm{O}, 8: 2\right)$ to yield $\mathbf{1}(18.7 \mathrm{mg}, 25.7 \mathrm{~min})$ and $\mathbf{2}$ $(11.2 \mathrm{mg}, 34.0 \mathrm{~min})$ from fraction 3 with flow rate of $1.0 \mathrm{~mL} / \mathrm{min}$, and $3(4.2 \mathrm{mg}, 14.1 \mathrm{~min})$ from fraction 2 with flow rate of $1.5 \mathrm{~mL} /$ min, respectively. Fraction 7 gave the main metabolite $4(263.0 \mathrm{mg})$ after purification by silica gel CC (400-600 mesh, $\mathrm{CHCl}_{3} / \mathrm{MeOH}$, $80: 1)$. Fraction 14 was purified by silica gel CC (400-500 mesh, $\left.\mathrm{CHCl}_{3} / \mathrm{MeOH}, 20: 1\right)$, and then separated by RP-HPLC $(\mathrm{MeOH} /$ $\left.\mathrm{H}_{2} \mathrm{O}, 7: 3,1.5 \mathrm{~mL} / \mathrm{min}\right)$ to yield $5(9.3 \mathrm{mg}, 25.2 \mathrm{~min})$.

Cytospolide 1: Colorless crystals $\left(\mathrm{CH}_{2} \mathrm{Cl}_{2}\right.$ /petroleum ether, 1:1). $R_{\mathrm{f}}$ $=0.61\left(\mathrm{CHCl}_{3}\right)$; m.p. $121-123^{\circ} \mathrm{C} \cdot[\alpha]_{\mathrm{D}}^{20}=-119.3(c=0.19$, in $\left.\mathrm{CHCl}_{3}\right) . \mathrm{CD}\left(\mathrm{CH}_{3} \mathrm{CN}, c=2.0 \times 10^{-4}\right): \lambda_{\max }(\Delta \varepsilon)=224.5(+0.99)$, $196(-18.27) \mathrm{nm} . \mathrm{CD}(\mathrm{KCl}) \lambda$ (mdeg), $1.70 \mathrm{mg}$ of 1 in $250 \mathrm{mg} \mathrm{KCl}$ : $225 \mathrm{sh}(-3.65), 198$ (-33.30). IR (film): $\tilde{v}=3506,2930,2859,1741$, 1670, 1510, 1459, 1376, 1238, 1177, 1107, 1066, 1020, 989, 912 $\mathrm{cm}^{-1}$. UV $\left(\mathrm{CH}_{3} \mathrm{CN}\right): \lambda_{\max }(\varepsilon)=221(2455) \mathrm{nm} \cdot{ }^{1} \mathrm{H}$ and ${ }^{13} \mathrm{C}$ NMR spectroscopic data see Table 1. HRMS (ESI) $\mathrm{m} / \mathrm{z}$ : calcd. for $\mathrm{C}_{17} \mathrm{H}_{28} \mathrm{O}_{5} \mathrm{Na}$ : 335.1834; found $335.1837[\mathrm{M}+\mathrm{Na}]^{+}$.

Cytospolide 2: Colorless oil; $R_{\mathrm{f}}=0.66\left(\mathrm{CHCl}_{3}\right) .[\alpha]_{\mathrm{D}}^{20}=-75.0(c=$ $0.11, \mathrm{CHCl}_{3}$ ). IR (film): $\tilde{v}_{\max }=3360,3196,2926,2854,1736,1664$, $1633,1461,1372,1238,1169,1102,1026,978 \mathrm{~cm}^{-1}$. UV $\left(\mathrm{CH}_{3} \mathrm{CN}\right)$ : $\lambda_{\max }(\varepsilon): 221$ (2156), 246 (1418), $256(1491) \mathrm{nm} .{ }^{1} \mathrm{H}$ and ${ }^{13} \mathrm{C}$ NMR spectroscopic data see Table 1. HRMS (ESI): $\mathrm{m} / \mathrm{z}$ : calcd. for $\mathrm{C}_{17} \mathrm{H}_{28} \mathrm{O}_{5} \mathrm{Na}, 335.1834$; found $335.1831[\mathrm{M}+\mathrm{Na}]^{+}$.

Cytospolide 3: Colorless oil; $R_{\mathrm{f}}=0.61\left(\mathrm{CH}_{2} \mathrm{Cl}_{2} / n\right.$-hexane, 20:1). $[\alpha]_{\mathrm{D}}^{20}=-54.7\left(c=0.04\right.$, in $\left.\mathrm{CHCl}_{3}\right)$. IR (film): $\tilde{\mathrm{v}}=2928,2856,1740$, $1454,1372,1236,1169,1108,1064,1022 \mathrm{~cm}^{-1}$. UV $\left(\mathrm{CH}_{3} \mathrm{CN}\right): \lambda_{\max }$ $(\varepsilon)=216(1581) \mathrm{nm} \cdot{ }^{1} \mathrm{H}$ and ${ }^{13} \mathrm{C}$ NMR spectroscopic data see 
Table 1. HRMS (ESI) $m / z$ : calcd. for $\mathrm{C}_{19} \mathrm{H}_{30} \mathrm{O}_{6} \mathrm{Na}, 377.1940$; found $377.1941[\mathrm{M}+\mathrm{Na}]^{+}$.

Cytospolide 4: Colorless oil; $R_{\mathrm{f}}=0.43\left(\mathrm{CHCl}_{3} / \mathrm{MeOH}, 10: 1\right) .[\alpha]_{\mathrm{D}}^{20}$ $=-89.5\left(c=0.38\right.$, in $\left.\mathrm{CHCl}_{3}\right) \cdot \mathrm{CD}\left(\mathrm{CH}_{3} \mathrm{CN}, c=2.4 \times 10^{-4}\right): \lambda_{\max }$ $(\Delta \varepsilon)=195(-10.19) \mathrm{nm}$. IR (film): $\tilde{v}=3436,2954,2929,2861$, $1718,1456,1375,1181,1101,1067,989,910 \mathrm{~cm}^{-1}$. UV $\left(\mathrm{CH}_{3} \mathrm{CN}\right)$ :

$451 \lambda_{\max }(\varepsilon)=222(2276) \mathrm{nm} .{ }^{1} \mathrm{H}$ and ${ }^{13} \mathrm{C}$ NMR spectroscopic data see Table 1. HRMS (ESI) $m / z$ : calcd. for $\mathrm{C}_{15} \mathrm{H}_{26} \mathrm{O}_{4} \mathrm{Na}$, 293.1729; found $293.1731[\mathrm{M}+\mathrm{Na}]^{+}$.

Cytospolide 5: Colorless crystals (ethyl acetate/petroleum ether, 2:1); $R_{\mathrm{f}}=0.42\left(\mathrm{CHCl}_{3} / \mathrm{MeOH}, 6: 1\right) ;$ m.p. $124-125^{\circ} \mathrm{C} .[\alpha]_{\mathrm{D}}^{20}=+33.3$ $456\left(c=0.09\right.$, in $\left.\mathrm{CHCl}_{3}\right) . \mathrm{CD}\left(\mathrm{CH}_{3} \mathrm{CN}, c=2.2 \times 10^{-4}\right): \lambda_{\max }(\Delta \varepsilon)=200$ $(+10.03) \mathrm{nm}$. IR (film): $\tilde{v}=3360,3193,3003,2924,2854,1706$, 1660, 1634, 1463, 1416, 1265, 1020, $976 \mathrm{~cm}^{-1}$. UV $\left(\mathrm{CH}_{3} \mathrm{CN}\right)$ : $\lambda_{\max }(\varepsilon)=221(2280) \mathrm{nm} .{ }^{1} \mathrm{H}$ and ${ }^{13} \mathrm{C}$ NMR spectroscopic data see Table 2. HRMS (ESI) $m / z$ : calcd. for $\mathrm{C}_{15} \mathrm{H}_{26} \mathrm{O}_{4} \mathrm{Na}, 293.1729$; found $293.1728[\mathrm{M}+\mathrm{Na}]^{+}$.

X-ray crystallographic studies of 1: A colorless needle-shaped crystal of 1 was obtained by recrystallization from $\mathrm{CH}_{2} \mathrm{Cl}_{2} /$ petroleum ether (1:1). $\mathrm{C}_{17} \mathrm{H}_{28} \mathrm{O}_{5}\left(M_{\mathrm{r}}=312.18\right)$, orthorhombic, space group $P 22_{1} 2_{1}$ with $a=5.2934(2) \AA, \quad b=$ 26.0941(10) $\AA, c=$ 26.6983(10) $\AA, a=\beta=\gamma=90.00^{\circ}, V=3687.7(2) \AA^{3}, Z=2, D_{\text {calcd. }}$. $=1.125 \mathrm{~g} / \mathrm{cm}^{3}, \lambda=1.542178 \AA$. Intensity data were measured with a Bruker SMART APEX-II CCD diffractometer $\left(\mathrm{Cu}-K_{\alpha}\right.$ radiation, graphite monochromator). A total of 10221 reflections were collected to a maximum $2 \theta$ value of $101.04^{\circ}$ at $296(2) \mathrm{K}$. The structure was solved by direct methods and refined by full-matrix leastsquares procedure. All non-hydrogen atoms were given anisotropic thermal parameters; hydrogen atoms were located from difference Fourier maps and refined at idealized positions riding on their parent atoms. The refinement converged at $R 1[I>2 \sigma(I)]=0.0571$,

$476 w R 2=0.1602$ for 10221 independent reflections and 401 variables; absolute structure parameter: $0.1(2)$.

X-ray Crystallographic Studies of 5: A colorless needle-shaped crystal of $\mathbf{5}$ was obtained by recrystallization from ethyl acetate/petroleum ether (2:1). $\mathrm{C}_{15} \mathrm{H}_{26} \mathrm{O}_{4},\left(M_{\mathrm{r}}=270.36\right)$, monoclinic, space group $P 2_{1}$ with $a=5.1384(4) \AA, b=36.752(2) \AA, c=8.7172(5) \AA, a=\gamma$ $=90.00^{\circ}, \beta=106.756(5)^{\circ}, V=1576.31(18) \AA^{3}, Z=2, D_{\text {calcd. }}=$ $1.139 \mathrm{~g} / \mathrm{cm}^{3}, \lambda=1.542178 \AA$. Intensity data were measured with a Bruker SMART APEX-II CCD diffractometer $\left(\mathrm{Cu}-K_{\alpha}\right.$ radiation, graphite monochromator). A total of 4876 reflections were collected to a maximum $2 \theta$ value of $133.86^{\circ}$ at 296 (2) $\mathrm{K}$. The structure was solved by direct methods and refined by full-matrix leastsquares procedure. All non-hydrogen atoms were given anisotropic thermal parameters; hydrogen atoms were located from difference Fourier maps and refined at idealized positions riding on their parent atoms. The refinement converged at $R 1[I>2 \sigma(I)]=0.0972$, $w R 2=0.2519$ for 3659 independent reflections and 352 variables.

CCDC-797932 (for 1) and -797933 (for 5) contain the supplementary crystallographic data for this paper. These data can be obtained free of charge from The Cambridge Crystallographic Data Centre via www.ccdc.cam.ac.uk/data_request/cif.

Acetylation of 1: To a solution of $\mathbf{1}(1.0 \mathrm{mg})$ in dry pyridine $(0.5 \mathrm{~mL})$ was added 1 drop of $\mathrm{Ac}_{2} \mathrm{O}$. The mixture was stirred at room temperature for $16 \mathrm{~h}$ to afford, after the usual work up, an sample identical to $\mathbf{4}$ in quantitative yield.

501 Acetylation of 2: Treatment of $\mathbf{2}(0.9 \mathrm{mg})$ with $\mathrm{Ac}_{2} \mathrm{O}$, using the above procedure, afforded an acetate in quantitative yield, identical to 4 .
Acetylation of 3: Treatment of $3(1.2 \mathrm{mg})$ with $\mathrm{Ac}_{2} \mathrm{O}$, using the above procedure, afforded an acetate in quantitative yield, identical to 4 .

Cytotoxicity Assay: The cytotoxic activity of tested compounds against the A-549 cancer cell line was assayed by the MTT [3-(4,5dimethylthiazol-2-yl)-2,5-diphenyltetrazolium bromide] colorimetric method. ${ }^{[13]}$ Adriamycin was used as the standard and exhibited an $\mathrm{IC}_{50}$ value of $0.4 \mu \mathrm{g} / \mathrm{mL}$.

Computational Section: Geometry optimizations [B3LYP/6-31G(d) level of theory, applying no or PCM solvent model for chloroform] and TD-DFT calculations were performed with Gaussian $03^{[14]}$ using various functionals (B3LYP, BH\&HLYP, PBE0) and TZVP basis set. CD spectra were generated as the sum of Gaussians ${ }^{[15]}$ with $3000 \mathrm{~cm}^{-1}$ half-height width (corresponding to $12 \mathrm{~nm}$ at $200 \mathrm{~nm}$ ), using dipole-velocity computed rotational strengths. Conformational searches were carried with Macromodel 9.7.211[16] software using MMFF with an implicit solvent model for chloroform. Boltzman distributions were estimated from the ZPVE corrected B3LYP/6-31G(d) energies in the gas phase calculations and from the B3LYP/6-31G(d) energies in the solvated ones. The MOLEKEL $^{[17]}$ software package was used for visualization of the results.

Supporting Information (see footnote on the first page of this article): Gas phase and solvent model conformational analysis of the truncated models of $\mathbf{1}$ and 5; experimental CD spectra of $\mathbf{4}$ and $\mathbf{5}$ compared with the computed TD-DFT CD spectra calculated for 5.

\section{Acknowledgments}

The research work was financially supported by the National Natural Science Foundation of China (NSFC) (grant numbers 30873200, 41076082), and the Shanghai Pujiang Program (PJ2008). The authors thank Prof. Sándor Antus (University of Debrecen) for discussions on CD and Dr. Attila Bényei (University of Debrecen) for his contribution to the X-ray analysis. T. K. thanks the National Office for Research and Technology, Hungarian Scientific Research Fund (NKTH, K-68429, OTKA, K-81701) TÁMOP 4.2.1./B-09/1/KONV-2010-0007 and the János Bolyai Foundation for financial support.

[1] G. Dräger, A. Kirschning, R. Thiericke, M. Zerlin, Nat. Prod. Rep. 1996, 13, 365-375.

[2] E. Demole, B. Willhalm, M. Stoll, Helv. Chim. Acta 1964, 47, $1152-1159$.

[3] a) A. Evidente, A. Cimmino, A. Berestetskiy, G. Mitina, A. Andolfi, A. Motta, J. Nat. Prod. 2008, 71, 31-34; b) A. Evidente, A. Cimmino, A. Berestetskiy, A. Andolfi, A. Motta, J. Nat. Prod. 2008, 71, 1897-1901; c) A. A. Sy, D. C. Swenson, J. B. Gloer, D. T. Wicklow, J. Nat. Prod. 2008, 71, 415-419; d) H. Greve, P. J. Schupp, E. Eguereva, S. Kehraus, G. M. König, J. Nat. Prod. 2008, 71, 1651-1653; e) S. Wu, Y. W. Chen, S. C. Shao, L. D. Wang, Z. Y. Li, L. Y. Yang, S. L. Li, R. Huang, J. Nat. Prod. 2008, 71, 731-734; f) Q. Tan, X. Yan, X. Lin, Y. Huang, Z. Zheng, S. Song, C. Lu, Y. Shen, Helv. Chim. Acta 2007, 90, 1811-1817; g) R. Nicoletti, M. P. Lopez-Gresa, E. Manzo, A. Carella, M. L. Ciavatta, Mycopathologia 2007, 163, 295-301; h) O. Yuzikhin, G. Mitina, A. Berestetskiy, J. Agric. Food Chem. 2007, 55, 7707-7711; i) W. Bhilabuyra, T. Techowisan, J. F. Peberdy, S. Lumyong, Res. J. Microbiol. 2007, 2, 749 755 ; j) V. Rukachaisirikul, S. Pramjit, C. Pakawatchai, M. Isaka, S. Supothina, J. Nat. Prod. 2004, 67, 1953-1955; k) T. S Bugni, J. E. Janso, R. T. Williamson, X. Feng, V. S. Bernan, M. 
Greenstein, G. T. Carter, W. M. Maiese, C. M. Ireland, J. Nat. Prod. 2004, 67, 1396-1399; 1) J. F. Rivero-Cruz, M. Macas, C. M. Cerda-Garca-Rojas, R. Mata, J. Nat. Prod. 2003, 66, 511-514; m) M. Tsuda, T. Mugishima, K. Komatsu, T. Sone, M. Tanaka, Y. Mikami, J. Kobayashi, J. Nat. Prod. 2003, 66 , 412-415; n) M. Chu, R. Mierzwa, L. Xu, L. He, J. Terracciano, M. Patel, V. Gullo, T. Black, W. Zhao, T. Chan, A. T. McPhail, J. Nat. Prod. 2003, 66, 1527-1530; o) A. Shimada, M. Kusano, K. Matsumoto, M. Nishibe, T. Kawano, Y. Kimura, Z. Naturforsch. B: Chem. Sci. 2002, 57, 239-242; $\square((<=$ Author: year/ volume do not match - for year 2002 the volume should be 57)) p) A. S. Ratnayake, W. Y. Yoshida, S. L. Mooberry, T. Hemscheidt, Org. Lett. 2001, 3, 3479-3481; q) S. Boonphong, P. Kittakoop, M. Isaka, D. Pittayakhajonwut, M. Tanticharoen, Y. Thebtaranonth, J. Nat. Prod. 2001, 64, 965-967; r) J. F. Rivero-Cruz, G. García-Aguirre, C. Cerda-García-Rojas, R. Mata, Tetrahedron 2000, 56, 5337-5344; s) A. Evidente, R. Capasso, A. Andolfi, M. Vurro, M. C. Zonno, Phytochemistry 1998, 48, 941-945; t) A. Evidente, R. Lanzetta, R. Capasso, A. Andolfi, M. Vurro, M. C. Zonno, Phytochemistry 1997, 44, 1041-1045; u) O. Papendorf, G. M. König, A. D. Wright, I. Chorus, A. Oberemm, J. Nat. Prod. 1997, 60, 1298-1300; v) J. Fuchser, A. Zeeck, Liebigs Ann./Recueil 1997, 87-95; w) M Inoue, H. Takenaka, T. Tsurushima, H. Miyagawa, T. Ueno, Tetrahedron Lett. 1996, 37, 5731-5734; x) A. Evidente, R. Lanzetta, R. Capasso, A. Andolfi, A. Bottalico, M. Vurro, M. C. Zonno, Phytochemistry 1995, 40, 1637-1641.

4] a) K. Ishigami, Biosci. Biotechnol. Biochem. 2009, 73, 971-979; b) V. B. Riatto, R. A. Pilli, M. M. Victor, Tetrahedron 2008, 64, 2279-2300; c) H. M. C. Ferraz, F. I. Bombonato, L. S. Longo, Synthesis 2007, 21, 3261-3285.

[5] a) A. Burns, G. McAllister, S. Shanahan, R. Taylor, Angew. Chem. Int. Ed. 2010, 49, 5574-5577; b) P. Srihari, B. Kumaraswamy, G. M. Rao, J. S. Yadav, Tetrahedron: Asymmetry 2010 , $21,106-111$; c) P. Prabhakar, S. Rajaram, D. K. Reddy, V. Shekar, Y. Venkateswarlu, Tetrahedron: Asymmetry 2010, 21, 216-221; d) P. Srihari, B. Kumaraswamy, D. C. Bhunia, J. S Yadav, Tetrahedron Lett. 2010, 51, 2903-2905; e) P. R. Krishna, T. J. Rao, Tetrahedron Lett. 2010, 51, 4017-4019; f) J. S. Yadav, K. A. Lakshmi, N. M. Reddy, A. R. Prasad, B. V. Subba Reddy, Tetrahedron 2010, 66, 334-338; g) P. Srihari, G. M. Rao, R. S. Rao, J. S. Yadav, Synthesis 2010, 2407-2412; h) P. S. Chowdhury, P. Gupta, P. Kumar, Tetrahedron Lett. 2009, 50, 7188-7190; i) D. K. Mohapatra, G. Sahoo, D. K. Ramesh, J. S. Rao, G. N. Sastry, Tetrahedron Lett. 2009, 50, 56365639; j) J. J. P. Selvam, K. Rajesh, V. Suresh, D. C. Babu, Y. Venkateswarlu, Tetrahedron: Asymmetry 2009, 20, 1115-1119; k) A. Kamal, P. V. Reddy, S. Prabhakar, Tetrahedron: Asymmetry 2009, 20, 1120-1124; 1) T. K. Chakraborty, R. Samanta, P. K. Kumar, Tetrahedron 2009, 65, 6925-6931; m) K. Rajesh, V. Suresh, J. Selvam, C. Rao, Y. Venkateswarlu, Helv. Chim. Acta 2009, 92, 1866-1872; n) P. S. Chowdhury, P. Gupta, P. Kumar, Tetrahedron Lett. 2009, 50, 7018-7020; o) J. G. Marrero, L. M. Harwood, Tetrahedron Lett. 2009, 50, 3574-3576; p) N. Jana, T. Mahapatra, S. Nanda, Tetrahedron: Asymmetry 2009, 20, 2622-2628; q) D. K. Mohapatra, U. Dash, N. Ramesh, Synlett 2009, 2129-2132; r) A. K. Perepogu, D. Raman, U. S. N. Murty, V. J. Rao, Bioorg. Chem. 2009, 37, 46-51; s) J. S. Yadav, N. Thrimurtulu, K. U. Gayathri, B. V. S. Reddy, A. R. Prasad, Tetrahedron Lett. 2008, 49, 6617-6620; t) C. Barfoot,
A. Burns, M. Edwards, M. Kenworthy, M. Ahmed, S. Shanahan, R. Taylor, Org. Lett. 2008, 10, 353-356; u) M. Matsuda, T. Yamazaki, K.-i. Fuhshuku, T. Sugai, Tetrahedron 2007, 63, 8752-8760; v) S. Ghosh, R. V. Rao, Tetrahedron Lett. 2007, 48, 6937-6940; w) P. Krishna, M. Narsingam, Synthesis 2007, 23, 3627-3634; x) X. S. Chen, S. J. Da, L. H. Yang, B. Y. Xu, Z. X. Xie, Y. Li, Chin. Chem. Lett. 2007, 18, 255-257; y) P. Gupta, P. Kumar, Tetrahedron: Asymmetry 2007, 18, 1688-1692; z) K. Nagaiah, D. Sreenu, R. S. Rao, J. S. Yadav, Tetrahedron Lett. 2007, 48, 7173-7176.

[6] a) W. Zhang, K. Krohn, Zia-Ullah, U. Flörke, G. Pescitelli, L. D. Bari, S. Antus, T. Kurtán, J. Rheinheimer, S. Draeger, B. Schulz, Chem. Eur. J. 2008, 14, 4913-4923; b) W. Zhang, K. Krohn, H. Egold, S. Draeger, B. Schulz, Eur. J. Org. Chem. 2008, 4320-4328; c) W. Zhang, K. Krohn, S. Draeger, B Schulz, J. Nat. Prod. 2008, 71, 1078-1081.

[7] G. Pescitelli, T. Kurtán, U. Flörke, K. Krohn, Chirality 2009, 21, E181-201.

[8] a) T. D. Crawford, Theor. Chem. Acc. 2006, 115, 227-245; b) C. Diedrich, S. Grimme, J. Phys. Chem. A 2003, 107, 2524 2539.

[9] a) T. Shi, S. M. Spain, D. L. Rabenstein, J. Am. Chem. Soc. 2004, 126, 790-796; b) F. W. Dahlquist, K. J. Longmuir, R. B. DuVirnt, J. Magn. Reson. 1975, 17, 406-410.

[10] a) M. Mayer, R. Thiericke, J. Antibiot. 1993, 46, 1372-1380; b) W. C. Snyder, K. L. Rinehart, J. Am. Chem. Soc. 1984, 106, 787-789.

[11] M. A. Fischbach, C. T. Walsh, Chem. Rev. 2006, 106, 34683496.

[12] a) K. Krohn, U. Flörke, M. S. Rao, K. Steingröver, H.-J. Aust, D. S. Draeger, B. Schulz, Nat. Prod. Lett. 2001, 15, 353-361; b) B. Schulz, J. Sucker, H.-J. Aust, K. Krohn, K. Ludewig, P. G. Jones, D. Doering, Mycol. Res. 1995, 99, 1007-1015.

[13] T. Mosmann, J. Immunol. Methods 1983, 65, 55-63.

[14] M. J. Frisch, G. W. Trucks, H. B. Schlegel, G. E. Scuseria, M. A. Robb, J. R. Cheeseman, J. A. Montgomery Jr., T. Vreven, K. N. Kudin, J. C. Burant, J. M. Millam, S. S. Iyengar, J. Tomasi, V. Barone, B. Mennucci, M. Cossi, G. Scalmani, N. Rega, G. A. Petersson, H. Nakatsuji, M. Hada, M. Ehara, K. Toyota, R. Fukuda, J. Hasegawa, M. Ishida, T. Nakajima, Y. Honda, O. Kitao, H. Nakai, M. Klene, X. Li, J. E. Knox, H. P. Hratchian, J. B. Cross, V. Bakken, C. Adamo, J. Jaramillo, R. Gomperts, R. E. Stratmann, O. Yazyev, A. J. Austin, R. Cammi, C. Pomelli, J. W. Ochterski, P. Y. Ayala, K. Morokuma, G. A. Voth, P. Salvador, J. J. Dannenberg, V. G. Zakrzewski, S. Dapprich, A. D. Daniels, M. C. Strain, O. Farkas, D. K. Malick, A. D. Rabuck, K. Raghavachari, J. B. Foresman, J. V. Ortiz, Q. Cui, A. G. Baboul, S. Clifford, J. Cioslowski, B. B. Stefanov, G. Liu, A. Liashenko, P. Piskorz, I. Komaromi, R. L. Martin, D. J. Fox, T. Keith, M. A. Al-Laham, C. Y. Peng, A. Nanayakkara, M. Challacombe, P. M. W. Gill, B. Johnson, W. Chen, M. W. Wong, C. Gonzalez, J. A. Pople, Gaussian 03, revision C.02, 2004, Gaussian Inc., Wallingford CT.

[15] P. J. Stephens, N. Harada, Chirality 2010, 22, 229-233.

[16] MacroModel, Schrödinger LLC, 2009; http://www.schrodinger.com/Products/macromodel.html.

[17] U. Varetto, MOLEKEL, v5.4, 2009, Swiss National Supercomputing Centre, Manno, Switzerland

Received: May 13, 2011 
Five nonanolides with an unprecedented 15-carbon skeleton, cytospolides $\mathbf{1}-\mathbf{5}$, were isolated from the endophytic fungus Cytospora $s p$. The structures were elucidated by spectroscopic analysis, chemical interconversion, and single-crystal X-ray diffraction analysis. The absolute configurations and conformations were determined by experimental methods and TD-DFT calcu-

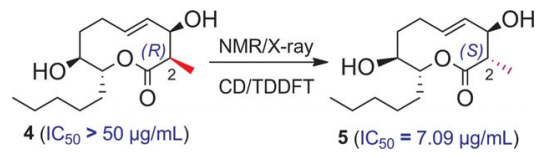

S. Lu, T. Kurtán, G. Yang, P. Sun,

A. Mándi, K. Krohn, S. Draeger,

B. Schulz, Y. Yi, L. Li, *

W. Zhang*

1-9

Cytospolides A-E, New Nonanolides from an Endophytic Fungus, Cytospora Sp.

Keywords: Natural products / Antitumor agents / Configuration determination / Nonanolide / Cytospolide 